\title{
Enhancement the Properties of Construction Urea Composition with Polymer Additive
}

\author{
Arslanov Islom Kimsanovich \\ Yeoju Technical Institute, Tashkent, Uzbekistan \\ Email: jasrash55@gmail.com
}

\begin{abstract}
This scientific article provides physicochemical studies where the addition of a gel polymer has a positive effect on the process of structure formation. The presence of chemical bonds between the components, a change in the morphology of the structure, a decrease in microporosity, an increase in the density and thermal stability of the urea composition are shown. Polymer composite materials are used as chemically resistant coatings, polymer mortars and polymer concretes. Along with such valuable properties as incombustibility, colorlessness, good miscibility with water, etc., urea resins and compositions based on them have a number of disadvantages. The object of the study is a carbamide composition with a quartz filler and an addition of a gel polymer, its structure formation and chemical resistance. The methodological basis of the study is the polystructural theory of composite building materials (CBM) and the modeling of the study of the chemical resistance of the urea composition in aggressive conditions. The issues of finding effective water-binding additives and studying their effect on structure formation, properties and technology of urea compositions remain relevant and require additional research. It is shown that with the optimal content of the gel-polymer additive in the composition of $0.13 \%$ of the filler weight, the compressive strength and specific impact strength increase by $17 ; 13 \%$ and shrinkage is reduced by $7 \%$. It was found that due to the enhancement of the adhesive bond between the components and the improvement of the pore structure under the action of the gel-polymer additive, the chemical resistance of the urea composition with quartz filler increases. So, water, acid and alkali resistance are $0.75 ; 0.80$ and 0.85 and which, respectively, are 6,7 and 7 points higher than the reference composition.
\end{abstract}

Keywords: Basic Properties, Gel Polymer, Quartz Sand, Urea Composition, Water Binder Additive.

\section{Introduction}

Polymer composite materials are used as chemically resistant coatings, polymer mortars and polymer concretes. Due to the low toxicity of urea-formaldehyde resins, construction composites based on them are most widely used.

It should be noted that along with such valuable properties as incombustibility, colorlessness, good miscibility with water, etc., urea resins and compositions based on them have a number of disadvantages: high internal stress during hardening, fragility, a large amount of chemically unbound water, low heat resistance, which make it difficult for practical use on a large scale.

The main direction of progress in the technology of urea compositions is the development of effective methods for binding free water formed in the process of oligomer polycondensation.

The strength and chemical resistance of urea compositions will be significantly improved if free water is bound, which is by-produced during the polycondensation of the resin and amounts to about $35-40 \%$ of the binder weight. Intensive release of free water during polycondensation of the urea oligomer is accompanied by high internal stresses, which leads to a decrease in crack resistance, the formation of defects in the structure, deterioration of the physical and mechanical properties and chemical resistance of composites based on it. The choice of effective water-binding additives is very difficult due to the acidic nature of the hardening of carbamide composites. Therefore, the search for effective acid-resistant waterbinding additives is an important stage in the development of urea composite materials. This 
can be achieved by using artificial and natural zeolites, polymeric and other substances, the products of new formation of which are water and chemically resistant $[7,8,11]$.

Analysis of the literature data showed that modern methods of obtaining polymer compositions based on urea resins do not guarantee the achievement of the required properties in terms of strength, specific impact strength, chemical resistance, etc. One of the ways to obtain chemically resistant urea compositions with improved deformation properties is chemical bonding of free water, which is side-released during the polycondensation of the resin in an amount of $35-40 \%$ by weight.

\section{Methods of research}

The previously proposed methods and means for modifying urea compositions did not adequately solve this problem.

Therefore, the issues of finding effective water-binding additives and studying their effect on structure formation, properties and technology of urea compositions remain relevant and require research $[1,3,4,5,6]$.

The methodological basis of the study is the polystructural theory of composite building materials (CMC) and the modeling of the study of the chemical resistance of the urea composition in aggressive conditions.

The aim of the study is to substantiate the possibility of obtaining a carbamide composition with a quartz filler and a water-binding additive - a gel polymer, which provides an improvement in the indicators of physical and mechanical properties and chemical resistance, as well as the establishment of patterns of its structure formation.

Slope of tasks:

- will reveal the mechanism of action of the hepolymer additive and its interaction with the components of the composition;

- to investigate the structure formation and optimize the composition of the carbamide composition with quartz filler and the addition of a gel polymer;

- to investigate the physical and mechanical properties and chemical resistance of the developed urea composition.

For the study, a carbamide composition with the following components was used:

carbamide resin KF-Zh, hardener - aniline hydrochloric acid (SKA), water-binding component of the gel polymer and filler - ground quartz sand.

The physicomechanical and operational properties of the urea composition with quartz filler and the addition of a gel polymer were investigated using standard methods. The structure formation of the urea composition was studied by physicochemical methods of analysis (DTA, IR spectroscopy, X-ray diffraction, differential porosity, and electron microscopy).

Optimization of the composition of the urea composition with quartz filler and the addition of a gel polymer was carried out by the method of mathematical planning of the experiment.

Recently, more and more attention of researchers has been attracted by the class of polyelectrolytes - hydrogels, for example, gel polymers with a macroreticular structure, possessing ion-exchange activity, the ability to multiple swelling in water and having sufficiently high physical and mechanical properties, as well as the possibility of their chemical modification in order to regulate properties. 
Helpolymers are substances that have the ability to absorb and retain a very large amount of moisture, sometimes hundreds of times their own weight. Gelpolymers are obtained from substances that do not dissolve in water, they are cross-linked polymers with a macroreticular structure. In their original state prior to hydration, they are similar to rigid polymers inflexible brittle and tough. When immersed in water, the hydroxyl groups of a dry polymer attract water molecules and the polymer absorbs water [2].

Experimental studies were carried out to study the effect of gel-polymer additives on the main physical and mechanical properties and to determine their optimal amount in the urea composition. When determining the dosage of the gel-polymer additive in the composition, the amount of free water released during the polycondensation of the urea-formaldehyde resin was taken into account. It is known that the maximum released free water during the polycondensation of the resin is $35-40 \%$ of the mass of the latter. Considering that $1 \mathrm{~g}$ of gel polymer has the ability to absorb $100 \mathrm{~g}$ of water, then for the maximum degree of $\%$ absorption, $0.35 \mathrm{~g}$ of gel polymer additives or $0.17 \%$ by weight of the filler must be added.

To absorb 25,50 , and $75 \%$ of free water, the gel polymer should be taken in an amount of $0.05 ; 0.09$ and $0.13 \%$ by weight of the filler, respectively.

The effect of the gel-polymer additive was assessed by the change in the compressive strength of the samples from the urea composition. For the experiments, urea compositions were prepared with different gel-polymer content from the weight of the filler at constant values of dispersion and degree of filling $[9,10]$.

Aniline hydrochloric acid (HA) was used as a hardener in an amount of $3 \%$ of the resin mass, and a filler was quartz flour with a degree of filling $\mathrm{Cv}=2$.

As a result of studies, it was found that the absorption effect and the calculated amount of bound water released during the polycondensation of the urea resin depend on the content of the gel-polymer additive in the composition. It is shown that when the content of the gelpolymer additives in the composition is $0.05 ; 0.09 ; 0.13$ and $0.17 \%$ binds $25,50,75$ and $100 \%$ free water. The extreme character of the change in the strength of the urea composition from the content of the gel-polymer additive with a maximum of the indicator at $0.13 \%$ of the filler weight was experimentally established. In this case, $R_{c z h}$ increases by $25 \%$ in comparison with the control composition.

It is known that the properties of a polymer composition depend significantly on the dispersion of the filler and its content. Therefore, studies of the effect of dispersion and degree of filling on the strength and specific impact strength of the composition with ground sand and the addition of a gel polymer have been carried out. The results of the performed experiments established the extreme nature of the change in these properties with a maximum of the indices pre: $\mathrm{S}_{\mathrm{sp}}=0.2 \mathrm{~m}^{2} / \mathrm{g}$ and the degree of filling $\mathrm{Cv}=2$. It was shown that the nature of the change in the studied properties does not depend on the content of the gel polymer additive.

In the structure formation of composite materials, the nature of the bond between the components is important. For this purpose, the nature of the interaction of the components in the hardened urea composition has been studied by IR spectroscopy. Studies have shown that the introduction of a gel-polymer additive in the urea composition in an amount of 0.05$0.17 \%$ does not significantly affect the changes in the structure of the urea composition. However, in the spectrum of compositions with a gel-polymer additive content of 0.05$0.13 \%$, a shift of absorption bands to the low-frequency region is observed, which refers to

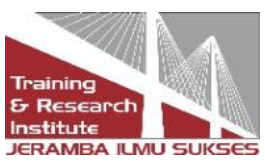


the absorption of $\mathrm{OH}$-groups associated with hydrogen bonds and is characterized by deformation vibrations of water in comparison with the additive content. At the same time, a higher value of the frequency of asymmetric stretching vibrations of the quartz sand included in the composition is observed. On this basis, it was concluded that there are chemical bonds between the components of the composition, due to the formation of less strong hydrogen bonds with the participation of $\mathrm{OH}$ groups of water and stronger hydrogen bonds with the participation of oxygen atoms of silicon dioxide.

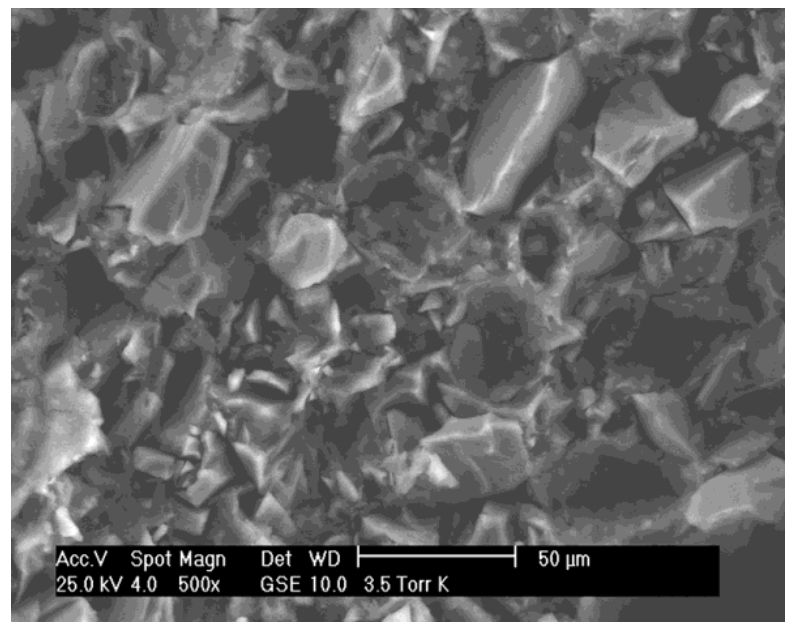

K-01

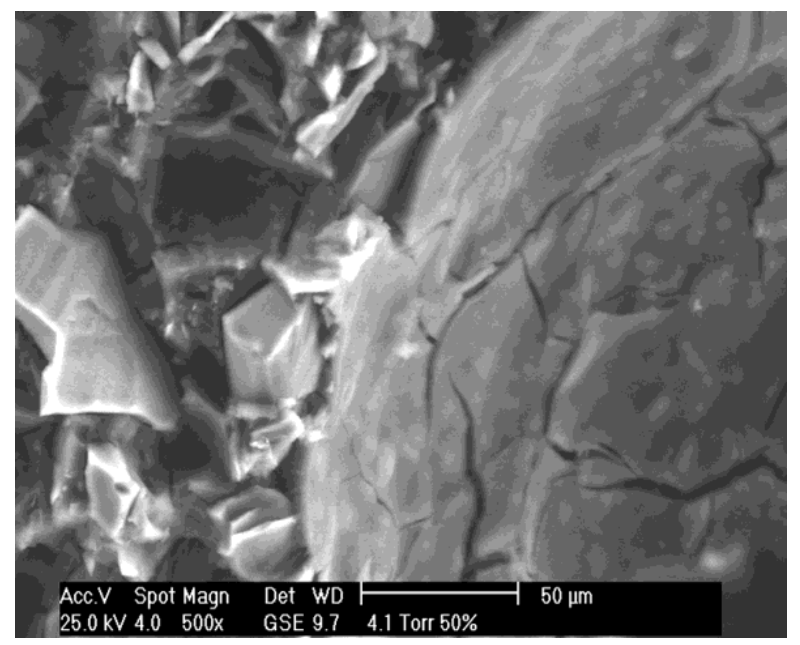

0,09-01

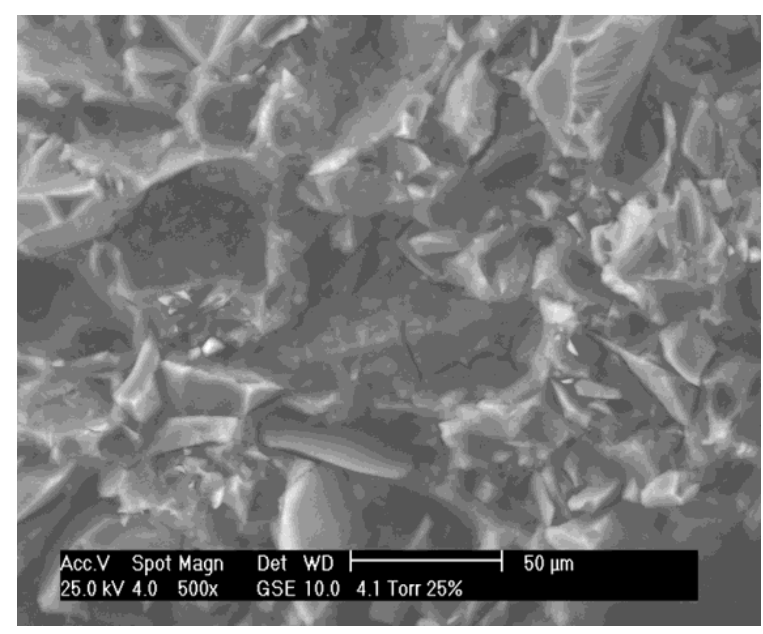

0,05-01

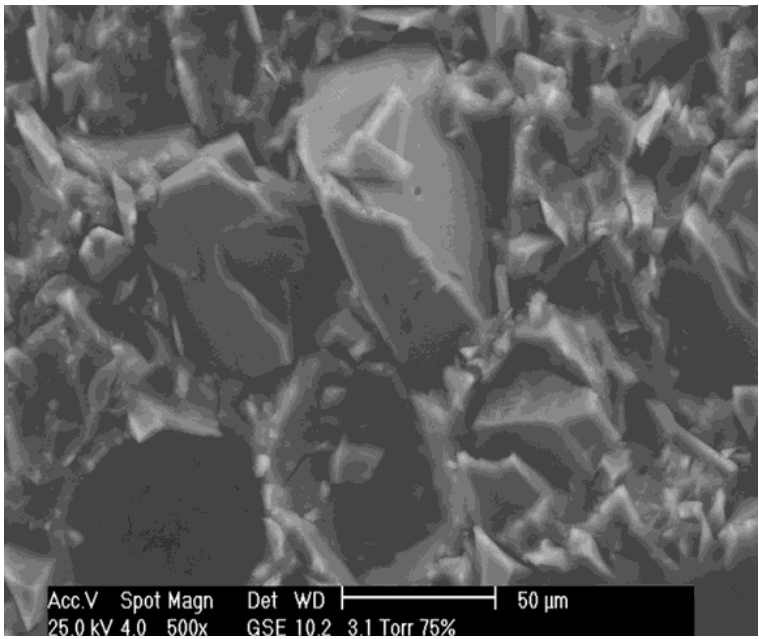

$0,13-01$ 


\section{$0,17-01$}

Figure 1. Microstructure of urea composition.

K-01 - urea composition without gel-polymer additives; 0.05-01; 0.19-01; 0.13-01; 0.17-01 urea composition with a gel-polymer additive content of $0.05,0.09,0.13$ and $0.17 \%$ by weight of the filler, respectively

For polymer composite materials, it is important not only the nature of the bond between the components, but also the morphology of the structure, including the supramolecular one. Electron microscopic studies have shown that due to the absorption of free water, the morphology of the structure of the urea composition changes significantly. In the latter, there is a transition from a block microstructure to a continuous crystallized mass.

The appearance of a pronounced interface is apparently explained by stresses arising from different coefficients of linear expansion of the filler and urea resin, and also the shrinkage of the latter during the curing process. The introduction of a gel-polymer additive into the composition of the urea composition leads to a change in the structure, makes the cleavage surface relatively smooth, absorbing and separating the internal stresses arising between the phases. Due to the presence of a water-binding additive, the surface of the composite is represented by globular lumpy - small formations on relatively round grains with low stepped areas (Figure 1.).

\section{Results}

The results of studies to determine the microporosity of the composition showed that the composition with the addition of a gel polymer has a total porosity of $0.1468-0.1507 \mathrm{~cm} 3 / \mathrm{g}$. In this case, micropores with a size of 0.01-100 microns make up 35-40\% of the total volume. Due to the absorption of free water by the gel-polymer additive, the microporosity of the composition is reduced. As a result of curing, the carbamide composition acquires a dense and strong structure. The best porosity values are achieved with the addition of $0.13 \%$ gel polymer.

The study of the rheological properties of the composition showed that the control composition has a pot life of 10-15 minutes. Due to the introduction of a water-binding component into the composition, an increase in these indicators is observed by 1.5 times. This is due to the fact that the gel-polymer additive has a plasticizing effect, and also, being absorbed on the surface of the filler particles, promotes the formation of lubricating shells that prevent particle aggregation and cause pentatization. Binding of free water contributes to the weakening of the adhesion forces between the individual particles and the ultimate shear stress of the mixture, as a result of which the polymer capacity decreases with increasing pot life.

Experimental data indicate that the strength of the compositions with the gel-polymer additive is higher by $13-17 \%$ in comparison with the control compositions. It was found that at the age of 30 days, the strength of the compositions increases most intensively and reaches 90\% of the maximum. Further study of strength growth shows that at the age of 90-180 days, the intensity of strength growth decreases.

Due to the introduction of a gel-polymer additive into the composition of the urea composition, the specific impact strength of the latter increases. It was found that the specific impact strength of the urea composition with quartz filler and the addition of a gel polymer is $13 \%$ higher compared to the control composition. It should be noted that in urea 
compositions with an increase in strength, an increase in specific impact strength is also observed. Based on this, it can be concluded that moisture retention during polycondensation of urea-formaldehyde resin with a gel-polymer additive contributes to an increase in impact resistance, as well as an improvement in the completeness of polymer cure due to the linear structure of the gel polymer, which gives a sufficiently high flexibility to polymer macromolecules.

Table 1. shows the main properties of the developed urea composition with the addition of a gel polymer.

Table 1. Properties of the urea composition with the addition of a gel polymer

\begin{tabular}{|c|c|c|c|c|c|c|}
\hline \multirow[t]{2}{*}{ № } & \multirow{2}{*}{ Indicators } & \multicolumn{5}{|c|}{ Property indicators for formulations } \\
\hline & & 1 & 2 & 3 & 4 & 5 \\
\hline 1 & $\begin{array}{l}\text { Ultimate strength, } \mathrm{MPa} \text {, in: compression } \\
\text { bending }\end{array}$ & $\begin{array}{l}70,0 \\
18,0\end{array}$ & $\begin{array}{l}80,5 \\
20,0\end{array}$ & $\begin{array}{l}84,5 \\
22,0\end{array}$ & $\begin{array}{l}85,0 \\
22,5\end{array}$ & $\begin{array}{l}84,0 \\
21,5\end{array}$ \\
\hline 2 & Specific impact strength, $\mathrm{J} / \mathrm{cm}^{2}$ & 0,26 & 0,27 & 0,29 & 0,30 & 0,30 \\
\hline 3 & Linear shrinkage, $\mathrm{mm} / \mathrm{m}$ & 68 & 66 & 65 & 63 & 64 \\
\hline 4 & Prismatic strength, $\mathrm{MPa}$ & 17,0 & 20,0 & 23,0 & 25,0 & 24,0 \\
\hline 5 & $\begin{array}{l}\text { Resistance coefficient after } 6 \text { months } \\
\text { exposure in: water } \\
3 \% \mathrm{H}_{2} \mathrm{SO}_{4} \\
10 \% \mathrm{NaOH}\end{array}$ & $\begin{array}{l}0,69 \\
0,73 \\
0,78\end{array}$ & $\begin{array}{l}0,73 \\
0,84 \\
0,80\end{array}$ & $\begin{array}{l}0,74 \\
0,78 \\
0,84\end{array}$ & $\begin{array}{l}0,75 \\
0,80 \\
0,85\end{array}$ & $\begin{array}{l}0,74 \\
0,80 \\
0,84\end{array}$ \\
\hline
\end{tabular}

The studies carried out also showed that the linear shrinkage of the control samples increases intensively in the first 1-2 days of hardening, when the resin polycondensation process takes place. During this period, the shrinkage kinetics is superimposed on the process of water evaporation from the surface, in which the molecular structure of the composition is rapidly compacted and microcracks appear in them. Intensive growth of linear deformations in urea compositions with a gel-polymer additive occurs in the first 1-3 days of hardening and its value is $5-7 \%$ lower than in the control. This is due to the fact that due to the introduction of a gel-polymer additive into the composition, the polymer system is plasticized and the water released from the microstructure is retained until the composition gains strength. During this period, the processes of polymerization and relaxation are more balanced, which undoubtedly has a positive effect on the deformative properties of the composition. By the age of 6 days, the compositions reach their maximum values and do not change with further exposure of the samples under normal conditions. The most intense shrinkage deformations are manifested in 
the initial hours of hardening of the composites during the transition of the binder from a liquid to a solid state, i.e. at the moment of structure formation, when there is a denser packing of molecules.

The chemical resistance of the developed composition has been investigated. It was found that the chemical bonding of free water with a gel-polymer additive provides an increase in acid resistance and alkali resistance of the composition by 7 points due to the formation of the most dense structure. The most acid-resistant and alkali-resistant is the carbamide composition containing 0.13 and $0.17 \%$ of the gel-polymer additive by weight of the filler.

\section{Conclusion}

1. Received urea composition with quartz filler with improved structure, increased physical and mechanical properties and chemical resistance by using a gel polymer additive in an amount that provides binding of $75 \%$ of free water released during the polycondensation of the resin.

1. The positive effect of the gel-polymer additive is due to a decrease in the hydrophilicity of the sand filler, a water-binding effect, an increase in the adhesive bond in the contact zone, plasticization of the polymer system, and an improvement in the morphology of the structure and its porosity.

2. Physicochemical studies have established that the addition of a gel polymer has a positive effect on the process of structure formation. The presence of chemical bonds between the components, a change in the morphology of the structure, a decrease in microporosity, an increase in the density and thermal stability of the urea composition are shown.

3. It is shown that with the optimal content of the gel-polymer additives in the composition of $0.13 \%$ by weight of the filler, the compressive strength and specific impact strength are, respectively, $17 ; 13 \%$ and shrinkage is reduced by $7 \%$.

4. It was found that due to the strengthening of the adhesive bond between the components and the improvement of the pore structure under the action of the gel-polymer additive, the chemical resistance of the urea composition with quartz filler increases. So, water, acid and alkali resistance are $0.75 ; 0.80$ and 0.85 and which, respectively, are 6,7 and 7 points higher than the reference composition.

\section{References:}

Akramov M.M. Urea compositions with activated phosphogypsum. Abstract of the thesis.... Candidate of Engineering Sciences - T.: TASI. 1993.-19 p.

Amirsaidov T.E. Technology for the synthesis of crosslinked polymers based on acrylic acid derivatives and their application. Abstract of thesis... Candidate of Engineering Sciences T.: TCTI. 2003.-19 p.

Arslanov I.K. Samigov N.A. Composite building materials with gel polymer additives. Abstracts of the 62nd Scientific and Technical Conference dedicated to NGASU (Sibstrin). April 6-7, 2005 - Novosibirsk. 36-37 p.

Akhmedov S.I. Polymer compositions based on a modified carbamide binder. Abstract of the thesis ... Candidate of Engineering Sciences - Alma-Ata. 1989.-18 p.

Zakirov J.S. Urea compositions for bio and chemical protection of reinforced concrete structures. Abstract of the thesis ... Candidate of Engineering Sciences - Tashkent. 1984.-19 p. 
Mavlyanov N.Kh. Urea polymer concrete with activated quartz fillers. Abstract of thesis...Candidate of Engineering Sciences - Saratov. 1989.-21 p.

Samigov N.A. Solomatov V.I. Urea polymer concrete technology. - Tashkent. Fan. 1987. $104 \mathrm{p}$.

Solomatov V.I. Polystructural theory of composite building materials. - Tashkent: Fan. 1991. - 345p.

N. Samigov, A. Dshalilov, I. Sidikov, I. Arslanov, S. Yussupova, U. Samigov. Structure und Eigenschaften eines Gelpolymerbetons

Ibauzil. 16. Internationale Baustofftagung. 20.-23. September 2006. Weimar. Bundesrepublic Deutschland. Tagungsbericht - band 2.p.2-0347-2-0354

Amirsaidov T.E. Samigov N.A., Ruziev R.R., Arslanov I.K. Modified urea compositions with gel polymer additives. Problems of energy saving and ecology in industrial and housing and communal complexes. Abstracts of the $\mathrm{V}$ International Scientific and Practical Conference. Penza. 49-51c. 2004

http://stroi-archive.ru/kompozity/1061-karbamidnye-kompozicii.html. Urea compositions $03 / 31 / 2016$ 